\title{
Implementing Jet Aircraft Training in a University Setting: Instructor Perceptions and Lessons Learned
}

\author{
Scott R. Winter, Jennifer E. Kirschner, Steven M. Leib, and Richard O. Fanjoy \\ Purdue University
}

\begin{abstract}
This paper presents the findings of a phenomenological study of instructor pilot first-hand experiences when conducting training for collegiate flight students in a jet aircraft. While jet training has been conducted in simulators in the past, this was one of the first instances of training in an actual aircraft. A total of 22 students completed training in a very light jet aircraft during the spring semester of their junior year at the subject university. A group of four instructors conducted both simulator and flight training with the students. Surveys were used to collect data from instructors longitudinally throughout the length of the 16-week semester. At the conclusion of the training period, participants completed a structured interview. The results of those interviews suggested that students excelled in areas such as avionics programming, use of standardized operating procedures, and checklist usage. Students were challenged by the increased operating speeds of the jet aircraft, descent planning, and lesson preparedness. The instructors offered suggestions to enhance the course and provided a summary of the lessons learned.
\end{abstract}

Authors' Note:

A portion of this work was previously presented at the Human Factors and Ergonomics Society's 56th Annual Meeting in Boston, MA October 22-26, 2012, in the Student Conference Proceedings.

\section{Introduction}

Within university flight training programs, the use of jet aircraft has typically been limited by high operating costs. While some training programs provide ride along observations, few, if any, provide formal training in an actual aircraft. However, the subject university recently purchased a very light jet (VLJ) for use in the flight-training curriculum. For the first time, instructors are providing training to low-time pilots during a 4-year professional flight degree who recently completed their multi-engine commercial certificates with an instrument rating. The experiences and perceptions of these instructors provide valuable information as the first cohort of students' complete training. The researchers will report on four areas of findings: responses to surveys, internal training challenges, external training challenges, and areas of student strengths. Finally recommendations that might be used to modify and improve the curriculum will be provided. This paper provides a synthesis of the collected data and provides recommendations for future areas of research.

\section{Aim of the Study}

This study was grounded in a qualitative, phenomenological approach. The aim was to collect first-hand experiences from the instructor pilots conducting simultaneous 
training in both a jet simulator and a jet aircraft to gather their perceptions on the strengths and challenges of students completing this course. Students enrolled in the subject university's professional flight program completed a 10-hour training course in the aircraft. The 10-hour course consists of approximately: 3 hours practicing maneuvers, takeoffs, and landings; 2 hours practicing instrument approaches; 1 hour practicing single-engine procedures and a simulated emergency descent; 2 hours of copilot orientation to complete an SIC endorsement; and 2 hours completing a line orientated flight training lesson. At the completion of training, students earn a second-incommand endorsement for the Phenom 100 aircraft and a high altitude endorsement.

Of special interest are the issues and perceptions of the instructors as the training program unfolded, the level of student performance, and the preparedness of students completing the training. As a goal of the study was to gather data on the lived experiences of instructors who had all experienced the same training environment, along with this approach to civilian, university flight-training, a phenomenological study was deemed the most appropriate method of study to capture this data (Creswell, 2007).

\section{Literature Review}

The review of literature is broken down into two major sections. First, the authors will provide a review of recent legislation that may change the minimum training requirements of airline first officers. While the direct impact of this legislation is still to be seen, it is expected to have an impact on university aviation flight-training programs. The second section will provide information on jet training issues identified in previous literature, with a focus on very light jets and the ability of piston aircraft pilots to transition to larger transport category aircraft.

\section{Impetus for a Training Change}

In response to concerns over the standards of airline safety, specifically at the regional airline level, President Obama signed the Airline Safety and Federal Aviation Administration Act of 2010 into law on August $1^{\text {st }}, 2010$. The repercussions of this new legislation are yet to be seen. One of the more prominent items is the requirement for all airline first officers to hold airline transport pilot certificates (111th Congress, 2010). While the scope of this legislation lies outside the current research project, it will likely have an impact on how universities complete flight training. A debate has begun within in the industry on how "safe" pilots are produced - by attaining a certain quantity of flight hours or through the quality of the flight training received.

The Aviation Accreditation Board International (AABI) and the University Aviation Association (UAA) jointly undertook the task of identifying the characteristics of pilots who were most successful during regional airline pilot training. Smith, Bjerke, NewMyer, Niemczyk, and Hamilton (2010) studied characteristics of pilots hired by regional airlines from 2005 to 2009 and attempted to address how these characteristics related to their 
success at regional airlines. Six regional airlines were contacted to participate in the study and provide data for the researchers to review. However, because there is currently little standardization required in terms of employment record keeping, the researchers could only review outcomes common among all six airlines. The two main outcomes reviewed were "(a) how many times did the pilot need to repeat the elements of indoctrination training, and (b) whether the pilot completed the full training program at the airline" (Smith et al., 2010, p. 77). In the results of their study, Smith et al. (2010), reported that more than half of the pilots reviewed during their study had an aviation-related bachelors degree, were flight instructors who had less than 1,000 hours of flight time, and did not have any prior airline experience. Pilots who completed training in a university flight environment did comparatively better at airline training then counterparts who completed training at a non-university part 141 program or through part 61 training. Research has begun to examine the minimum experience necessary for first officers, and this study examines the practical issues that can arise when instructing collegiate students in a jet aircraft. It was also found that the group that was most successful were those pilots who had 501-1000 flight hours, compared to groups consisting of 178-500, 1001-1500, or greater than 1500 hours. While the study provides interesting information, the authors did note a small effect size. Recommendations for further research into this topic included a need to identify standardized parameters across the surveyed airlines to ensure simultaneous and similar data collection prior to the analysis.

\section{Jet Aircraft Training and Transition Issues}

The International Very Light Jet Training Stakeholders' Discussion Group surveyed 389 stakeholders about VLJ training practices currently used throughout the country (Barnes, 2008). Respondents expressed concern that "VLJs may experience a surge of early deliveries and rapid growth followed by a series of tragic and preventable humancaused accidents" (p. 2). Similarly, a review of National Transportation Research Board (NTSB) accident and incident reports found that VLJ pilots were more likely than pilots of other types of aircraft to have difficulty with landings, experience low fuel situations, be unfamiliar with aircraft avionics, not have flown recently, use poor crew (or single pilot) resource management, and lose situational awareness (Burian, 2007). Lack of experience in a particular aircraft is a common thread in all of these situations. Operating jets substantially increases the complexity and performance demands on pilots (Burian \& Dismukes, 2007). Despite this, VLJs are growing in popularity with little apparent change in the assessment and selection process of pilots.

While the European Joint Aviation Authority (JAA) is in the process of designing a required training program for all type ratings - VLJs included - the FAA has yet to establish a minimum experience level beyond that required to fly any multi-engine aircraft: a private pilot license with multi-engine rating (Barnes, 2008). The National Business Aviation Association (NBAA) has recommended that manufacturers conduct a "flight skills assessment" with each potential VLJ pilot, and consider an applicant's "experience and knowledge, recency of experience, background, and type of experience" 
to determine a candidate's likelihood of success in a training program (National Business Aviation Association, 2005, section 3.1).

Casner (2003) studied a sample of pilots during training to see how familiarization with a small aircraft GPS system would transfer to an airline style flight management system (FMS). Two experiments were completed. In the first, students who completed training on the GPS were able to complete $77 \%$ of the tasks on the FMS, a statistically significant improvement over the control group that received no prior instruction. In the second part of the study, participants were either given a self-study course or dual instruction on light piston aircraft automation. Participants that completed the self-study course did slightly better in the actual practice of those skills than did the participants in the dual instruction course. In a later study, Casner (2005) trained a group of participants to be proficient in a technologically advanced aircraft (TAA). The experimental group and an untrained control group then completed tasks in a jet transport aircraft simulator. The trained group was able to complete $83 \%$ of the tasks, compared to $54 \%$ of the control group (Casner, 2005). The findings of these two studies suggest that light piston aircraft automation may provide a positive transfer of learning to jet aircraft. The subject university of the current study utilizes a fleet of technologically advanced aircraft, with a similar avionics package to the VLJ, to complete primary training.

\section{Method}

\section{Participants}

All four instructor-pilots who volunteered to participate in the study served as training captains and completed training in both the simulator and jet aircraft. The participants consisted of one female and three males; all had prior experience in Part 121 operations. Study participants averaged 9,125 total flight hours - 7,600 hours in turbine operations, 1,260 hours of dual given, and four type ratings. The average age of participants was just under 45 years old. Three participants were trained in civilian flight programs and one participant had completed military flight training. Only instructors responsible for student training in both the simulator and jet aircraft were selected, excluding instructors who only supervise simulator training. Participants were solicited via an introductory e-mail and all volunteered to participate in the study. A limitation of this study was the small sample size, which may limit the generalizability of the findings.

\section{Materials}

The researchers distributed three paper surveys (at the beginning, middle, and end of the course) and conducted an in-person interview (at the end of the course). The surveys were administered electronically and participants' had the option of completing them online or by hand. At the conclusion of the project, interviews were conducted with all participants. Interviews were recorded, transcribed, and reviewed for accuracy by the 
researchers. The audio recordings were then deleted to preserve the anonymity of participants.

\section{Research Design and Procedure}

Interviews are typically the most common data collection tool within a phenomenological study (Creswell, 2007). However, because this was an exploratory study into a new experience, the researchers also decided to utilize survey instruments to collect data longitudinally to support the development of interview questions. The surveys were administered three times throughout the longitudinal study and given to participants at the beginning, middle, and end of the spring 2012 semester. Surveys attempted to capture the changing perceptions of instructors throughout the length of the training program. The survey instruments were constructed specifically for this research study. Content validity was obtained through analysis by aviation researchers with a background in providing training in jet aircraft. Participant surveys were examined longitudinally to examine responses for consistency and reliability. All survey items used open-ended, essay-style responses. Topics for response included perceptions of the training program, student strengths, student challenges, and overall program assessment. After all training was completed; interviews were conducted, ranging in length from 45 to 75 minutes. Interviews were semi-structured: all participants answered a series of approximately 20 questions, with follow-up questions added as deemed relevant, based on survey responses. All surveys were coded by hand. Interviews were coded both by hand and with the assistance of a qualitative software analysis tool. From the data analysis, the researchers grouped meaningful statements into larger themes. These themes are discussed in the results section and supported with statements from the participants. When coding the data, researchers used bracketing to account for their own experiences. Bracketing is the recognition that researchers have personal experiences, and it is an attempt to set aside those prior experiences to view the data with a fresh perspective (Creswell, 2007).

\section{Results and Discussion}

\section{Survey Responses}

The initial survey instrument was used to evaluate participants' concerns and issues regarding areas where students were likely to excel. Participants identified Garmin 1000 GPS operation, radio communications, standard operating procedures (SOP's), cockpit flows, checklist usage, and decision making as strong skills they expected the students to demonstrate during the training program. None of the four participants identified aircraft control as a skill at which the students were likely to excel. The participants stressed two major areas that may be problematic for new students: operating as part of a crew, and keeping up with the fast paced environment of the jet aircraft. 
When asked to express their concerns about students completing the training, the participants also focused on external issues. They agreed that the weather was a major concern and nearly all of them indicated aircraft availability (due to the number of students and the busy schedule of the aircraft) as factors that threated training completion and limit students' flight hours. Concern over descent planning and adjustment to the increased operating speed of jet aircraft were also expressed. Table 1 summarizes the strengths and challenges instructors anticipated for student performance from the first survey instrument.

Table 1

Initial Instructor Expectations for Student Performance

\begin{tabular}{|c|c|c|}
\hline Instrument & Anticipated Strengths & Anticipated Challenges \\
\hline Survey 1 & $\begin{array}{ll}\text { - } & \text { Avionics programming } \\
\text { - } & \text { Standard operating } \\
\text { procedures } \\
\text { - } & \text { Flow patterns and } \\
\text { checklist usage } \\
\text { - } & \text { Decision-making } \\
\end{array}$ & $\begin{array}{ll}\text { - } & \text { Adjusting to higher jet } \\
& \text { airspeeds } \\
\text { - } & \text { Operating as a crew } \\
\text { - } & \text { Descent planning } \\
\text { - } & \text { Weather } \\
\text { - } & \text { Scheduling issues } \\
\end{array}$ \\
\hline
\end{tabular}

At the mid-point of the training program the participants indicated that students were performing checklists, standard operating procedures, and utilizing the Garmin avionics well; all items that participants anticipated students would be successful with completing. The anticipated challenge areas participants indicated on the initial survey were also observed. Instructors commented on how students were struggling to adjust to the faster speeds of operating the jet aircraft and the associated time management and prioritization required to accomplish tasks. Students were also challenged by some external factors such as the live air traffic control environment and busy airspace. These concepts will be discussed further in the external challenges section. The final area of note on the midpoint surveys was instructor concern with poor student preparation before flight and poor recall of memory items. Adequate time for pre- and post-flight briefings will be addressed in the internal challenges section.

Comments on the final survey indicated students continued to perform well using checklists, standard operating procedures, and avionics, although there was some lack of proficiency incorporating the auto flight control system (AFCS) with the avionics. Aircraft speed and descent planning were areas still challenging to students. Instructors also discussed issues students experienced when completing non-scripted items like the transition from en-route flight to traffic patterns with visual approaches. The instructors felt confident that the course provided a successful initial experience for students mastering the skills required to operate a jet aircraft in the national airspace system. A summary of the mid-point and final surveys is summarized in Table 2. 
Table 2

Observed Strengths and Challenges of Jet Students

\begin{tabular}{|c|c|c|}
\hline Instrument & Observed Strengths & Observed Challenges \\
\hline Survey 2 & $\begin{array}{l}\text { - } \text { Checklist usage } \\
\text { - } \quad \text { Standard operating } \\
\text { procedures } \\
\text { - } \quad \text { Avionics programming }\end{array}$ & 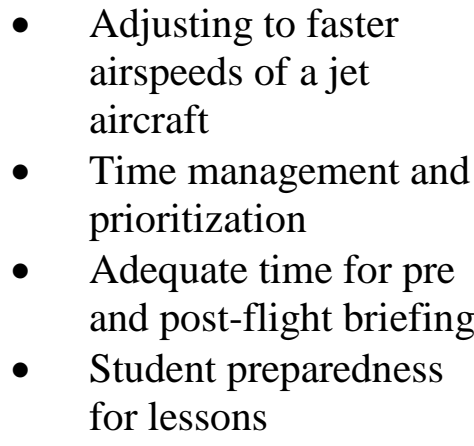 \\
\hline Survey 3 & $\begin{array}{l}\text { - } \quad \text { Checklist usage } \\
\text { - } \quad \text { Standard operating } \\
\text { procedures } \\
\text { - Avionics programming }\end{array}$ & $\begin{array}{ll}\text { - } & \text { Aircraft speed } \\
\text { - } & \text { Descent planning } \\
\text { Dealing with non- } \\
\text { scripted items and } \\
\text { situation awareness }\end{array}$ \\
\hline
\end{tabular}

Survey responses were used to develop interview questions. Once the interviews were competed and transcribed, a search for common themes commenced. When addressing challenges faced by students, instructor pilots seemed to identify two themes: internal challenges and external challenges. The researchers defined internal challenges as those over which instructor pilots could exercise control, while external changes were those items caused by nature or other variables. The researchers also identified areas where students showed strength in the training program and provided suggestions for course improvement.

\section{Internal Challenges}

Internal challenges relate to items such as physical resources, time constraints for preand post-flight briefings, changing course objectives, and student preparedness. When developing the training schedule, there was a limit on physical resources: a single aircraft and four instructors. The aircraft was scheduled for two-hour time blocks, which copied the piston-training schedule at the subject university. However, an area of concern that arose from this type of scheduling was its limiting impact on pre- and post-flight briefing time. When instructors were scheduled with back-to-back lessons, it severely limited the amount of time for pre- and post-flight briefing time available for students because of the minimal time between flight lessons. All the instructors recognized this limitation and the need for more briefing time. Instructors recommended structuring the schedule to follow more of a Part 121 or military style of flight training, where 30-60 minutes of pre-flight briefing occur before flight and an additional 30-60 minutes of post-flight briefing upon 
return. The instructors felt that this change would allow time to discuss both the lesson objectives and the tasks to be completed during the lesson. One participant emphasized that as the one item he/she would change if it were possible to start the semester over, "I'd get more time for... briefing and debriefing the students." Another instructor commented, "If we had some pre-brief time ahead of time...the lessons would have been more productive too." A suggested change may be an attempt to alter the schedule of instructors in a way that would allow the aircraft to operate efficiently yet not force instructors in back-to-back training sessions, which limits the amount of pre- and postflight briefing time.

The "moving target" for course objectives was another challenge for the instructors. These objectives ranged from a basic familiarization course to possibly preparing some students for a type rating. "The objective of the course seems to be a moving target mostly because of the NPRM [notice of proposed rule making]," stated one participant. Understandably, the instructors had very limited goals for this first semester of training. Safety remained a prominent goal throughout the training program. "My approach, with no apologies, is I was going to be ultra conservative," explained one participant. As the program developed, it became clear that some students excelled faster than others. A suggestion of the instructors was to develop a tiered training program. An example of the tier system may require a certain letter grade in the ground school and simulator course before operating in the left seat of the jet, otherwise the student would be limited to the right seat. Instructors also encouraged an additional program that would allow the top percentage of students to complete an elective course in pursuit of a type rating. Students would have to be recommended by all or a majority of instructors to enroll in this course.

An internal challenge that was unanticipated was a lack of student preparedness. Instructors recounted how some students arrived unprepared for flights or without the necessary materials completed before the flight. One instructor commented, "I probably should have stressed some things more, of being more prepared when you show up." Some students also seemed to lack a thorough knowledge of cockpit memory items. A possible explanation for this is the difference in training environments between Part 121/military and university environments. In airline/military environments, the flight course is the primary responsibility of participants, whereas for university students, the flight-training course is just one of their responsibilities each semester. A participant commented, "It's the nature of the beast with the academic schedule to run that, unlike an airline training program, part 135 or part $91 \mathrm{~K}$ training facility, this isn't their only course." In the university environment, students are busy with other courses, projects, and activities. Instructors anticipated students would show up prepared for lessons, and it was somewhat surprising that some struggled in this role. A possible explanation may be the varying levels of maturity. College students may still be adjusting to their role as adult learners, and it may take some longer than others to accept the responsibility that accompanies operating a jet aircraft. Instructors have suggested the use of quizzes before certain flight lessons as a tool to motivate and confirm students are staying current on operating procedures, memory items, and limitations. 


\section{External Challenges}

External challenges identified by instructors were weather and situational awareness. The training program took place during the spring semester at the subject university, located in the Midwestern portion of the United States. This led to various weather situations from snow and ice to heat and humidity with thunderstorms. Instructors had to consider a number of factors when working to decide what weather minimums should be used for training because the jet could conduct training in situations that would normally ground a piston training aircraft. All instructors acknowledged the impact weather had on the training program. The instructors did feel that enough time was built into the program for student training completion as the weather improved later in the semester.

Situational awareness was an issue that instructors identified as challenging students - specifically involving external components such as air traffic control, other traffic, and situations that were not well scripted. This manifested most often during visual approaches to airports. In the simulator course completed prior to flying the jet, emphasis was placed on flying instrument approaches. Instrument approaches are standardized and very precisely timed, with the same tasks completed at the same points along every approach. However, when on a visual approach, these standardized procedures transition to the discretion of the student pilot. The student must decide when to slow down, how to enter the pattern (unless otherwise instructed), how long to make the pattern legs. Students would often wrestle with some of these decisions. Once the aircraft was maneuvered onto a leg of the pattern, students were able to resume the normal landing profile and comply with the standard operating procedures. However, the transition portion between the en-route phase of flight and entering the pattern was often haphazard. It was suggested that additional time be spent in the simulator conducting visual approaches to better prepare students for the aircraft.

Study participants suggested the training curriculum include line oriented flight training (LOFT) in the simulator phase, including visual approaches in an attempt to provide a more real-world experience with which students may have to deal during an actual flight. LOFT and scenario-based training provide real-world situations and put the student in situations where decisions must be executed using available information, as occurs in a real aircraft.

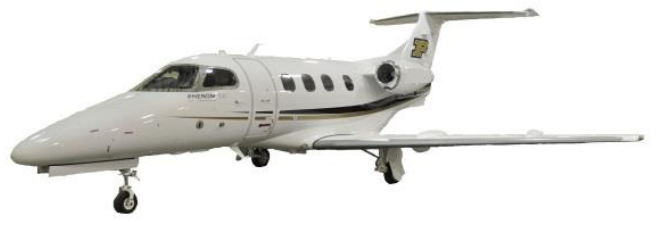

\section{Strengths}

A strength identified by the instructor pilots was the aircraft, an Embraer Phenom 100 aircraft depicted in Figure 1. This is aircraft is categorized as a very light jet (VLJ) and is certified for single-pilot operations. The aircraft is typically operated in five training slots, four days per

Figure 1. Phenom 100 Aircraft. 
week; at times, it completed up to 35 cycles per day. It was also used for select university trips, which necessitated the need to balance student training with official university business.

An area where instructors felt students excelled was in the use of the avionics. The Phenom uses a variation of the Garmin G1000 cockpit, called Prodigy. Before flying the Phenom 100, students completed primary training in a Garmin G1000 cockpit, called Perspective, found in a piston-training aircraft. It was anticipated that students' prior experience and familiarity with Garmin avionics would provide a positive transfer of learning into the jet aircraft. "I would say without Garmin experience there's no way they could do this course. There's absolutely no way," cited one participant. The instructors anticipated this strength, and it was observed throughout the training program. All the instructors felt students were able to program the avionics efficiently, however, a few expressed concern over whether the students fully comprehended how the programming functions actually linked with the other avionics, specifically the autopilot. One participant noted, "Well, every student was really competent on the Garmin... the difficulty they had was translating from the Garmin to the autopilot flight control system, the AFCS." Very few of the piston trainers with which students were familiar included autopilots. Instructors identified a learning curve as students became more familiar with the autopilot in the Phenom. A suggested improvement would be to have students gain more experience with the autopilot during the primary portions of training or at least prior to entering the Phenom aircraft to assist in learning transfer.

A final focus area of the instructors was the continued need for instructor standardization. While this initial semester only utilized four instructor pilots, as the program develops more instructors may be needed. It is also desired to provide a level of standardization that no matter which instructor completes training, it will be the same experience for the student. It should be noted that this program was unique to a university environment, and all members of the jet training team contributed to develop training and standardization materials, which are continually updated as more experiences are gained. Table 3 depicts a summary of student challenges, strengths, and suggestions for improvement that were derived from final participant interviews.

\section{Conclusions}

This study utilized a phenomenological approach to capture the first-hand experiences of four instructor pilots who trained a group of university students in a jet aircraft. Researchers completed a series of surveys with participants and a final interview to capture their perceptions on how students performed during the training. Instructors correctly anticipated that students would experience a positive transfer of learning in operating the Garmin avionics, standard operating procedures, flow patterns, and checklists. Instructors also accurately anticipated areas that would challenge students such as the increased operating speeds of the jet aircraft, descent planning, weather, and 
aircraft scheduling. After completing the interviews, the researchers identified both internal and external challenges for jet flight training.

Table 3

Summary of Student Challenges, Strengths, and Suggestions

\begin{tabular}{|c|c|c|c|c|}
\hline Instrument & $\begin{array}{c}\text { Internal } \\
\text { Challenges }\end{array}$ & $\begin{array}{c}\text { External } \\
\text { Challenges }\end{array}$ & Strengths & Suggestions \\
\hline Interview & 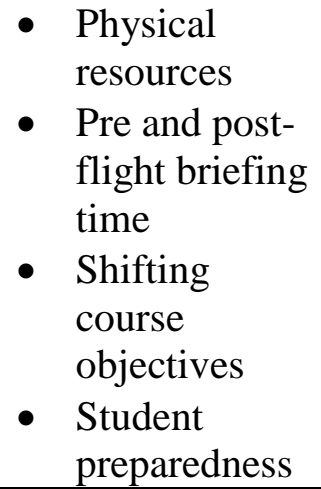 & $\begin{array}{ll}\text { - } & \text { Weather } \\
\text { - } & \text { Situation } \\
& \text { awareness }\end{array}$ & $\begin{array}{ll}\text { - } & \text { Aircraft } \\
\text { - } & \text { Avionics } \\
& \text { program } \\
& \text { ming }\end{array}$ & $\begin{array}{l}\text { - Use of Line } \\
\text { Oriented Flight } \\
\text { Training and } \\
\text { scenarios } \\
\text { - } \quad \text { Tiers of } \\
\text { training } \\
\text { - } \quad \text { Instructor } \\
\text { standardization }\end{array}$ \\
\hline
\end{tabular}

Internal challenges included availability of physical resources, pre- and post-flight briefing time, shifting course objectives, and student preparedness. Instructors expressed the need for sufficient pre- and post-flight briefing time to properly prepare students for flight lessons, yet also recognized limitations on physical resources such as instructor and aircraft scheduling demands. Concern was expressed that students needed to master procedural knowledge and arrive prepared for flights. Suggested improvements include increased briefing times and quizzes to verify knowledge retention and motivate students to keep studying. Instructors emphasized the need for students to arrive for lessons prepared, even though university environments demand student attention to other courses.

External challenges include those items over which the instructors were unable to exercise control. The weather impacted training early in the spring semester, but the instructors felt that there was enough time to make-up training later in the semester as the weather improved. Another item instructors identified was the difference between operating in a scripted environment, such as the simulator, versus the real world. External factors such as other aircraft and live air traffic control challenged students, especially when items required pilot discretion. Instructors have recommended increasing the number of visual approaches during simulator work to provide students with an opportunity to practice decision-making skills during transition from the en-route phase of flight to the traffic pattern with little or no help from air traffic control. Students were well prepared with their knowledge and understanding of programming the avionics, although some struggled with incorporating those avionics in conjunction with the automatic flight control system. Other suggestions include the use of scenarios in the training program and utilization of the principles from line oriented flight training. 
Tiers of training may address those students who are not as quick to catch on to the challenges of flying a jet or the lack the maturity level required to assume that responsibility. It may also offer the top percentage of students the chance to pursue advanced jet training. A possible limitation to a tiered system may be physical resources and time, and an additional cost to the student. Finally, standardization was recognized as needing further attention as additional groups of students complete training. Future research should focus on instructor perceptions of training cohorts, and trainee perceptions of their preparation and progress. 


\section{References}

$111^{\text {th }}$ Congress. (2010). Airline safety and federal aviation administration act of 2010. H.R 5900 .

Barnes, R. B. (2008). Ensuring VLJ safety: Learning to ask the right questions SAE Technical Publication Series 2008-01-2239. Wichita, KS: SEA.

Burian, B. (2007). Very light jets in the national airspace system. In Proceedings of The $14^{\text {th }}$ International Symposium on Aviation Psychology. Dayton, OH: Wright State University.

Burian, B. \& Dismukes, K. (2007). Training the VLJ Pilot. Mountain View, CA: NASA.

Casner, S. M. (2003). Learning about cockpit automation: From piston training to jet transport. National Aeronautics and Space Administration, Ames Research Center. Moffett Field: NASA.

Casner, S. M. (2005). Transfer of learning between a small technically advanced aircraft and a commercial jet transport simulator. International Journal of Applied Aviation Studies, 5(2), 307-319.

Creswell, J. W. (2007). Qualitative inquiry and research design: Choosing among five approaches. Thousand Oaks, Sage.

National Business Aviation Association. (2005). Very light jet training guidelines. Retrieved from http://www.nbaa.org/ops/safety/vlj/.

Smith, G. M., Bjerke, E., NewMyer, D. A., Niemczyk, M., \& Hamilton, R. A. (2010). Pilot source study: An analysis of pilot backgrounds and subsequent success in US regional airline training programs. International Journal of Applied Aviation Studies, 10(1), 73-96.

Winter, S. R., Kirschner, J.E., Leib, S. M., \& Fanjoy, R.O. (2012, October). Perceptions of instructors on student training in a jet aircraft: A preliminary qualitative analysis. Paper session presented at the Student Conference of the Human Factors and Ergonomics Society's $56^{\text {th }}$ Annual Meeting, Boston, MA. 